\title{
Early Detection of Covid-19 in Canadian Provinces and its Anticipatory Measures for a Medical Emergency
}

\author{
Vikram Kumar Kamboj ${ }^{1,3} \cdot$ Chaman Verma $^{2}$. Anish Gupta ${ }^{4}$
}

Received: 5 September 2020 / Accepted: 24 September 2020 / Published online: 19 October 2020

(c) The Author(s) 2020

\begin{abstract}
The spread of COVID-19 is incearsing day by day and it has put the entire world and the whole humankind at the stack. The assets of probably the biggest economies are worried because of the enormous infectivity, and transmissibility of this ailment. Because of the developing extent of the number of cases and its ensuing weight on the organization and wellbeing experts, some expectation strategies would be required to anticipate the quantity of evidence in the future. In this paper, we have utilized time series forecasting approach entitled autoregressive integrated moving average, and bend fitting for the forecast of the quantity of COVID-19 cases in Canadian Province for 30 days ahead. The estimates of different parameters (number of positive cases, number of recouped cases, and decrease cases) got by the proposed strategy is exact inside a specific range, and will be a beneficial apparatus for overseers, and wellbeing officials to organize the clinical office in the distinctive Canadian Province.
\end{abstract}

Keywords ARIMA $\cdot$ Canadian province $\cdot$ Covid-19 $\cdot$ Decease $\cdot$ Confirmed

\section{Introduction}

In the unexpected pandemic (Covid-19), every human being is living in a fearful environment, and obviously, it is spreading out rapidly and effected the human's life. In December 2019. All world is confronting a century pandemic

This article is part of the topical collection "Computational Statistics" guest edited by Anish Gupta, Mike Hinchey, Vincenzo Puri, Zeev Zalevsky and Wan Abdul Rahim.

Chaman Verma

chaman@inf.elte.hu

Vikram Kumar Kamboj

vikram.23687@lpu.co.in

Anish Gupta

gupta.anish1979@gmail.com

1 Department of Electrical and Computer Engineering, Schulich School of Engineering, University of Calgary, Calgary, Canada

2 Department of Media and Educational Informatics, Eötvös Loránd University, Budapest, Hungary

3 Domain of Power System, School of Electronics and Electrical Engineering, Lovely Professional University, Phagwara, India

4 ABES Engineering College, Ghaziabad, India
Coronavirus, which has been spreading at an extremely high fast speed from the finish of 2019. Presenting in December 2019, right off the bat, it had tainted a Chinese human in Wuhan on 30th January 2020, China [1]. The official declaration of this novel pneumonia episode a "worldwide pandemic" on the eleventh walk by the World Health Organization (WHO) (Wang et al. [1]) and given another name Covid-19. Covid-19 has been moved from creature to human and directly; it is dissipating in all mainlands. The absence of any forestalling antibody demonstrated hazardous to human life. All segments, for example, training, accommodation, transportation, exchanging and so on., and a lot more are not affected by this worldwide pandemic. As of 21 st May 2020, out of an aggregate of 4,893,186 affirmed cases, 3,23,256 passings are affirmed in the entire world [2]. A few analysts from the globe have been attempting to foresee Covid-19 cases. Pestilence improvement drifts in South Korea, Italy, and Iran were anticipated utilizing forward expectation and in backward induction [3]. Using bend fitting and repetitive neural system, future Covid-19 positive cases and affirmed cases were distinguished in India [4]. Canada has an aggregate of ten Provinces, and three territories and Covid-19 additionally begin affecting since 30th January 2020 when the main case was seen from Chines inception [5]. The present research study has prime focus on 
the prediction of Covid-19 cases w.r.t. different parameters such as number of positive cases, number of recouped cases, and decrease cases. The proposed research work will be a beneficial apparatus for overseers, and wellbeing officials to organize the clinical office in the distinctive Canadian Province. The following are the major highlights of the proposed research work:

- Expert modeler forecasting has been proposed for COVID-19 in Canadian Provinces.

- Thirty days of day-ahead estimation for different parameters has been made.

- Analysis of the impact of lockdown, social separation, and effect of change proportion.

- Forecasting and an understanding of conceivable circumstances in the coming days have been reported.

- Predicting of the relationship of deceased patients with recovered and confirmed patients has been made.

- Predicting the decease and confirmed cases in the distinct Provinces.

\section{Literature Review}

The epidemic comes into picture at wet market (Wuhan city) in China. The first recognized cases have found some symptoms like problem in the respiratory system, sneezing, dry coughing, and fever. But there was no any proof that this virus spread due to this wet market in Wuhan city [6]. Some researchers also said that this virus can also come due to

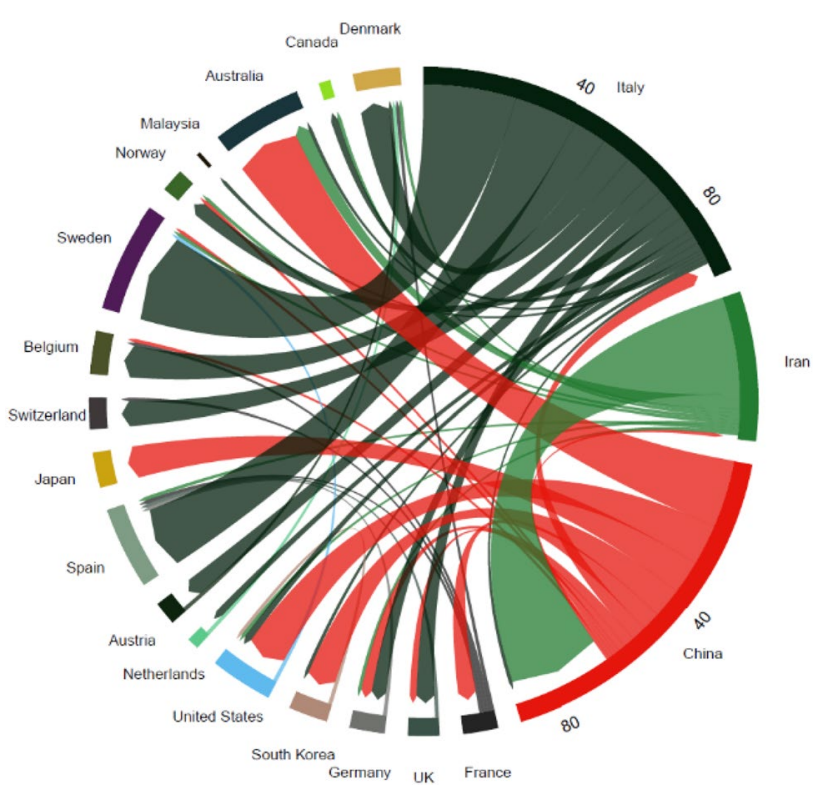

Fig. 1 Initial transmissions of Covid-19 between most heavily affected regions taking the soup of bats, but it is not proven yet. But after sometime this virus spread slowly in more than 34 provinces in China and 25 other countries resulting in 75,199 confirmed cases and 2009 deaths [7]. Then, the World health organization has given a statement that this virus has a tendency to spread from human to human and also called this disease as Coronavirus (Covid-19) [8]. After increasing the number of patients, China started some action plans against fighting this disease like lockdown in the whole country, sanitized all necessary places, and complete quarantine of every citizen. As on 12th May 2020, the world corona meter showing the total number of cases in China is 82,919 , from which 4633 have lost their life and 78,171 have recovered

Table 1 ARIMA models for confirmed cases

\begin{tabular}{ll}
\hline British Columbia & $\operatorname{ARIMA}(0,2,2)$ \\
Grand Princess & $\operatorname{ARIMA}(0,1,8)$ \\
Manitoba & $\operatorname{ARIMA}(0,2,1)$ \\
New Brunswick & $\operatorname{ARIMA}(1,2,2)$ \\
New Fondland and Labrador & $\operatorname{ARIMA}(1,2,0)$ \\
Nova Scotia & $\operatorname{ARIMA}(0,2,4)$ \\
Ontario & $\operatorname{ARIMA}(0,2,0)$ \\
Prince Edward Island & $\operatorname{ARIMA}(2,2,9)$ \\
Quebec & $\operatorname{ARIMA}(2,2,0)$ \\
Saskatchewan & $\operatorname{ARIMA}(0,2,6)$ \\
\hline
\end{tabular}

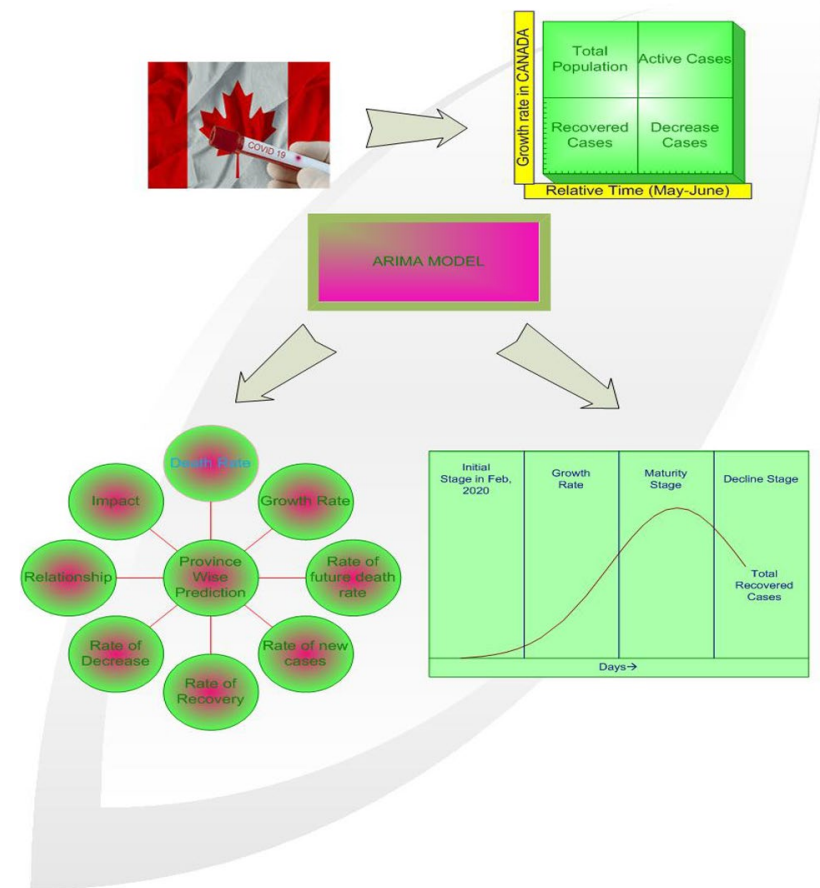

Fig. 2 Proposed schematic diagram for Canadian research study 


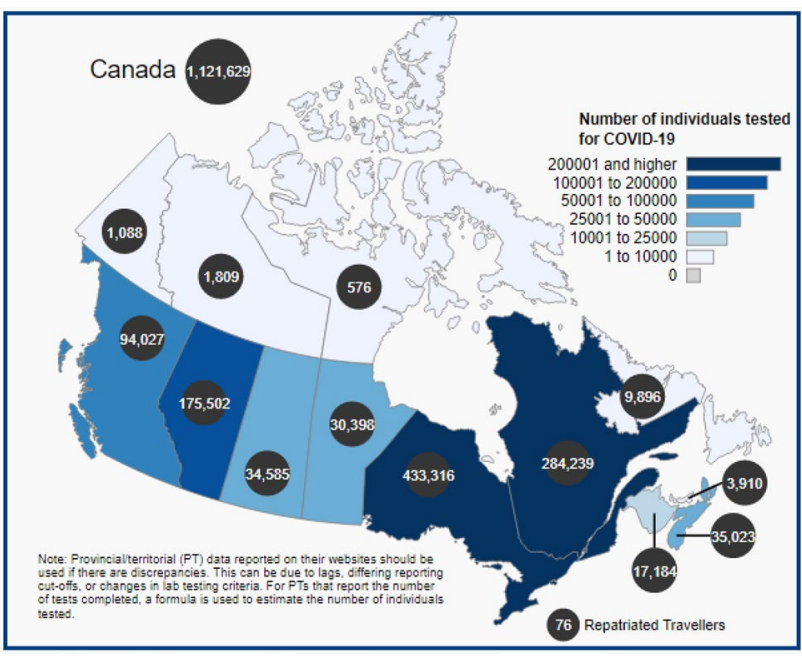

Fig. 3 Total number of Individual tested

from this dangerous virus. Due to the mobility of the people from one country to another this virus has been spread almost all over the world. The total number of cases due to this virus is $4,268,496$ from which 287,463 have lost their lives and 1,533,701 have recovered from this virus till 12th May 2020. Now a days, this virus has become a massive threat for all over the world. Because there is no proper drugs and vaccine prepared yet, this virus also drops a massive impact on the whole economy of the world, which is continuously decreasing. Coronavirus has a shell, the particles are round or oval, often pleomorphic, and 50-200 nm in diameter as shown in Fig. 1. S-protein lies on the virus surface, creating a rod-shaped structure [9]. As one of the virus' most essential antigenic proteins, the $\mathrm{S}$ protein gene is the primary target used for typing. Xu et al. also stated that SARS-CoV-2 S-protein supports a strong association with human angiotensin-converting enzyme 2 (ACE2) molecules, which means that S-protein-ACE2 binding pathway poses a major public health risk to human transmission [10]. Awareness of coronavirus physical and chemical characteristics mainly comes from SARS-CoV and MERS-CoV studies. The coronaviruses are heat-sensitive and can be destroyed for $30 \mathrm{~min}$ at $56^{\circ} \mathrm{C}$. Besides, the virus can be effectively inactivated by ether, $75 \%$ ethanol, chlorine disinfectant, peracetic acid, and chloroform, but not by chlorhexidine [11]. Figure 1 depicts the initial transmission of Covid-19 between profoundly affected regions in the world.

Everyday growth rate of affected patients is increasing rapidly. Therefore, keeping this fact in mind, a predictive analysis was performed to estimates the possible count of death of affected patients in Canada. This paper is structured into four sections. Section 1 debated on the introductory theory of Covid-19 with focusing on Canadian impact. Section 2 designed research schema important objectives and relative hypotheses. Section 3 focused on predictive analytical techniques. Section 4 describes the test data under consideration. Section 5 executed experiments with sufficient discussions. Section 6 concluded the major essence of the study.

\section{Proposed Methodology}

We used the SPSS expert model for the forecasting of confirmed and decease cases in the Canadian provinces. Based on specific parameters, it spontaneously recognizes and
Table 2 Total number of individual tested versus confirmed cases as on 11 May, 2020

\begin{tabular}{llrr}
\hline Province, territory or other & $\begin{array}{l}\text { Total number of individu- } \\
\text { als tested }\end{array}$ & $\begin{array}{l}\text { Total number of con- } \\
\text { firmed cases }\end{array}$ & $\begin{array}{l}\text { Total } \\
\text { number of } \\
\text { deaths }\end{array}$ \\
\hline Canada & $11,21,629$ & 69,981 & 4,993 \\
Newfoundland and Labrador & 9896 & 261 & 3 \\
Prince Edward Island & 3910 & 27 & 0 \\
Nova Scotia & 35,023 & 1019 & 48 \\
New Brunswick & 17,184 & 120 & 3,013 \\
Quebec & $2,84,239$ & 38,469 & 1,669 \\
Ontario & $4,33,316$ & 20,546 & 7 \\
Manitoba & 30,398 & 289 & 6 \\
Sakatchewan & 34,585 & 568 & 117 \\
Alberta & $1,75,502$ & 6300 & 130 \\
British Columbia & 94.027 & 2353 & 0 \\
Yukon & 1088 & 11 & 0 \\
Northwest territories & 1809 & 5 & 0 \\
Nunavut & 576 & 0 & 0 \\
Repatriated travellers & 76 & 13 & 0 \\
\hline
\end{tabular}



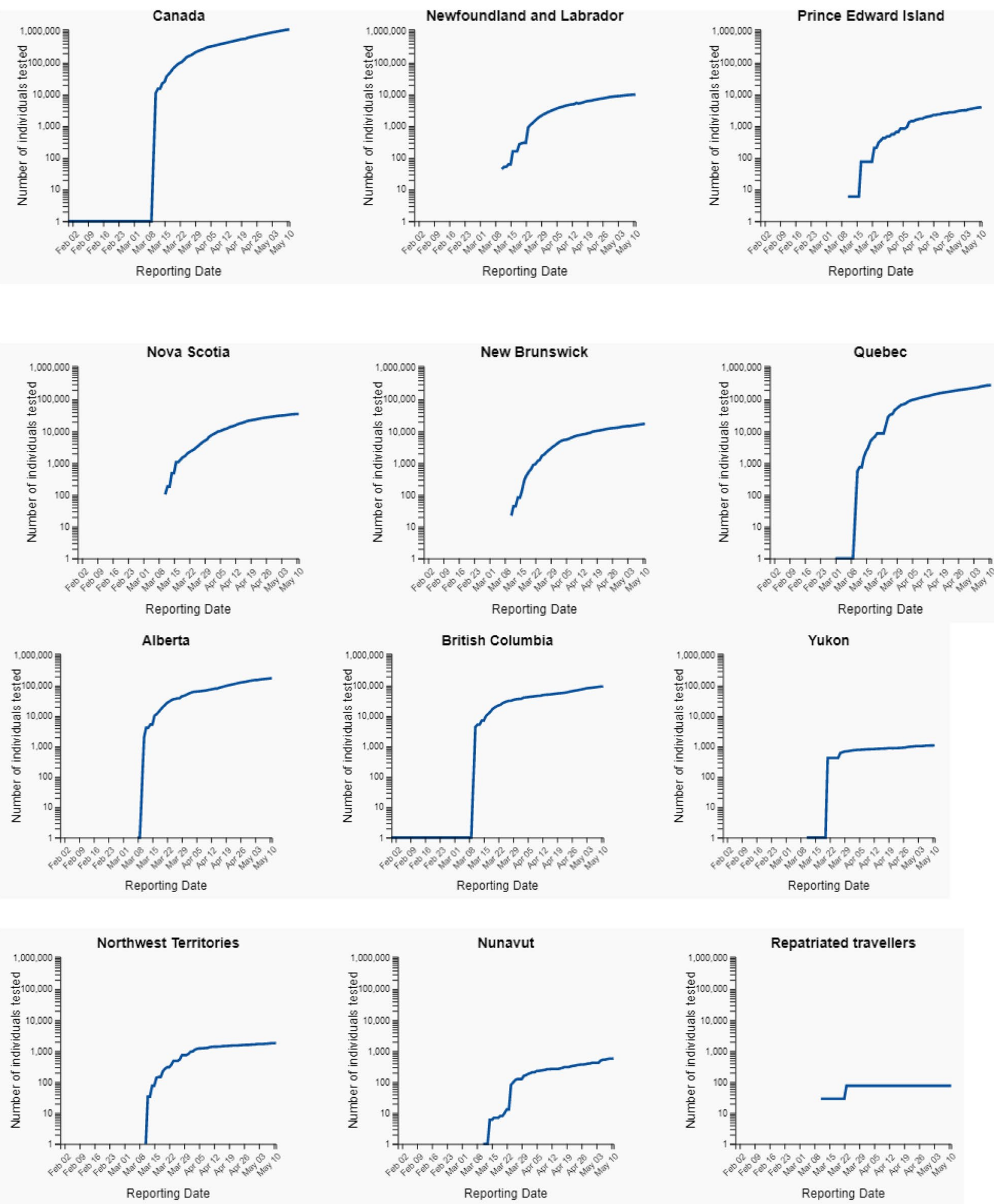

Fig. 4 Total number of individual tested up to 11 May 2020 (log scale) 

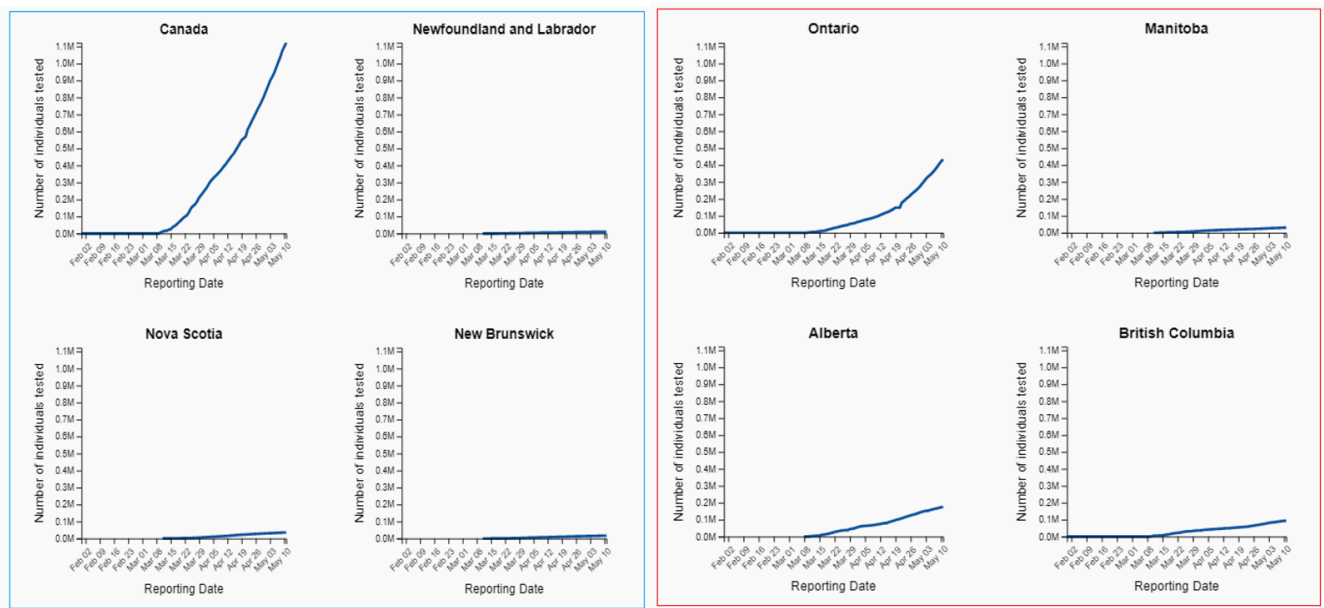

(a)

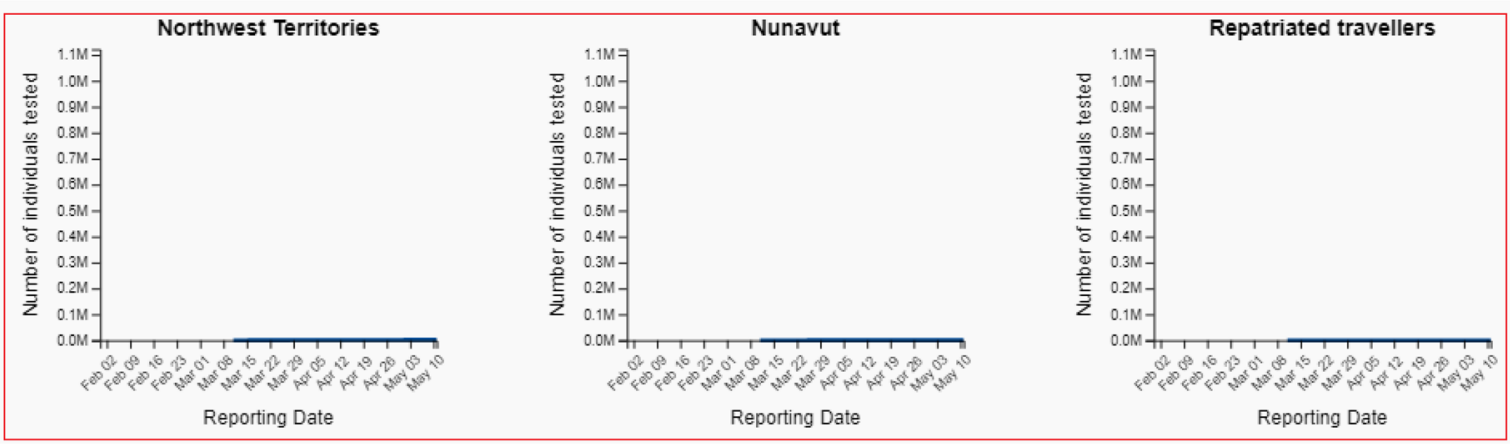

(b)
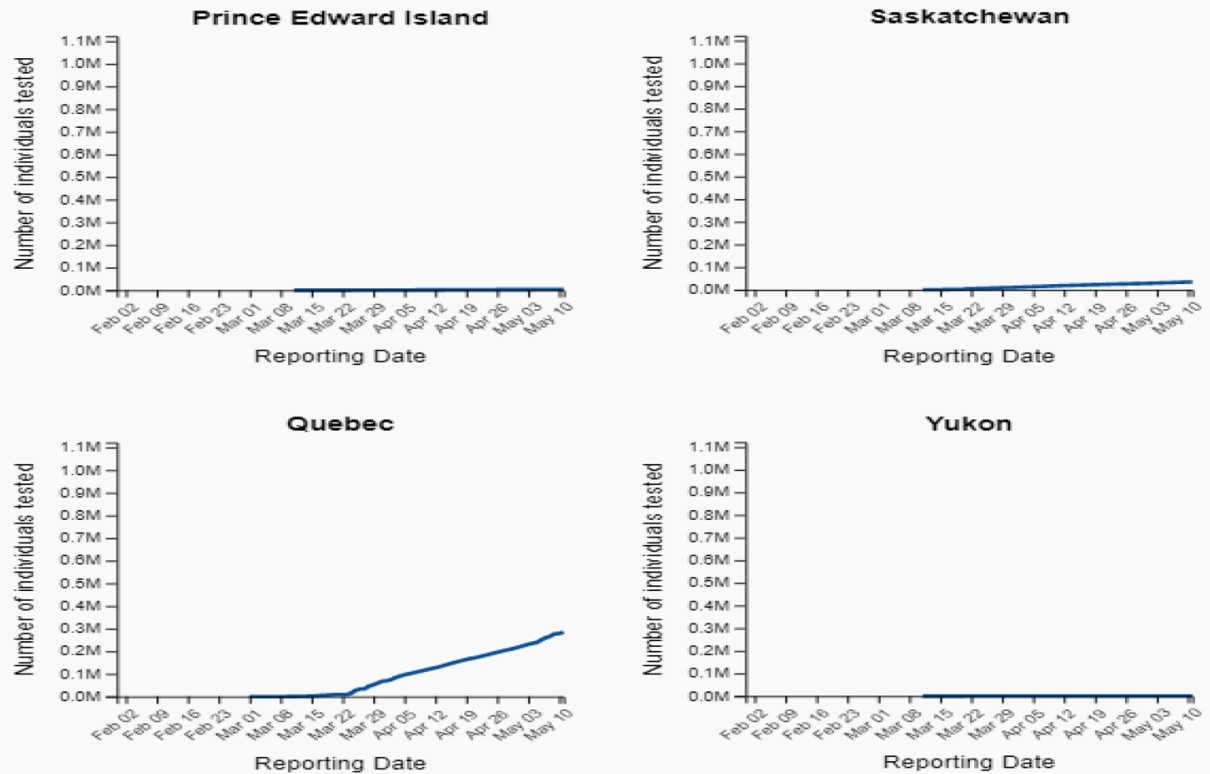

(c)

Fig. 5 a Total number of individual tested upto 11 May, 2020 (normal scale). b Total number of individual tested upto 11 May, 2020 (normal scale). c Total number of Individual tested upto 11 May, 2020 (normal scale) 


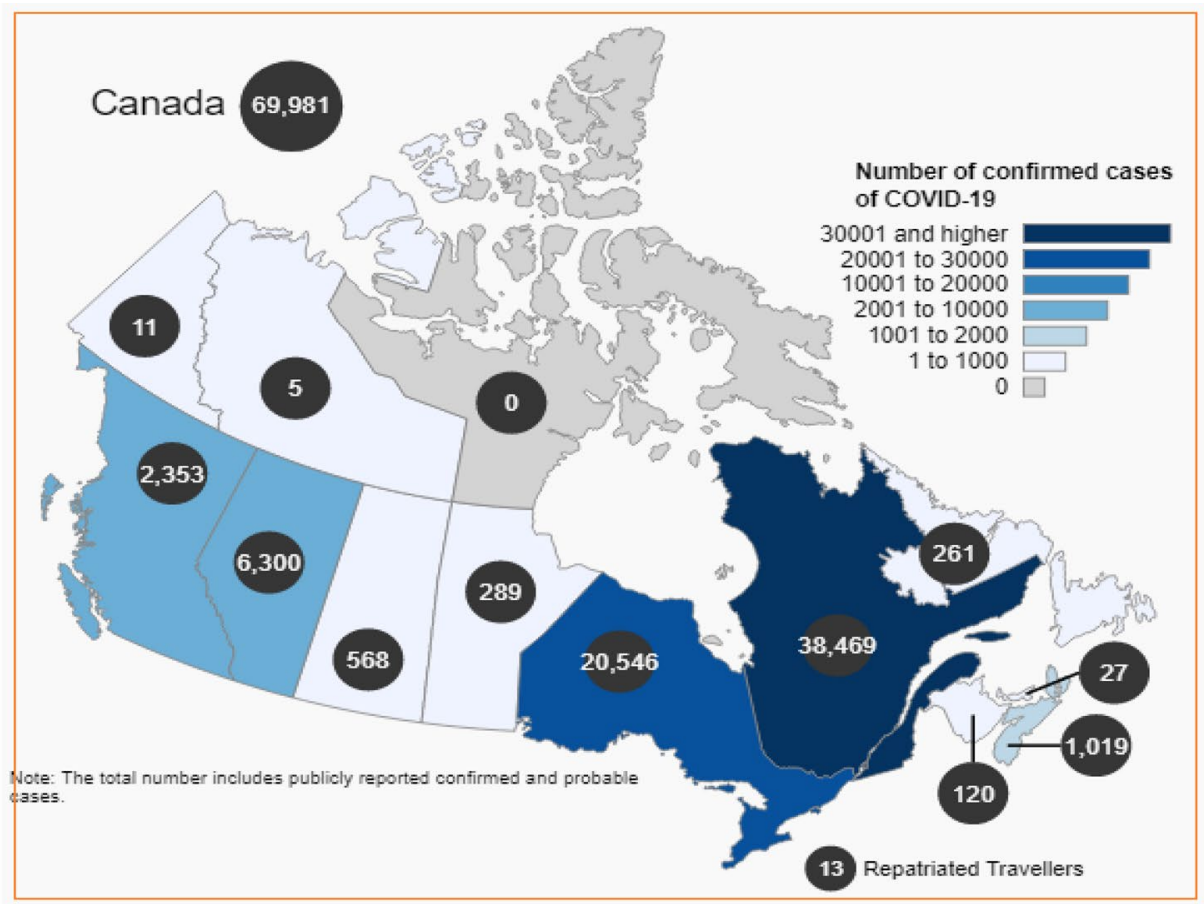

(a)
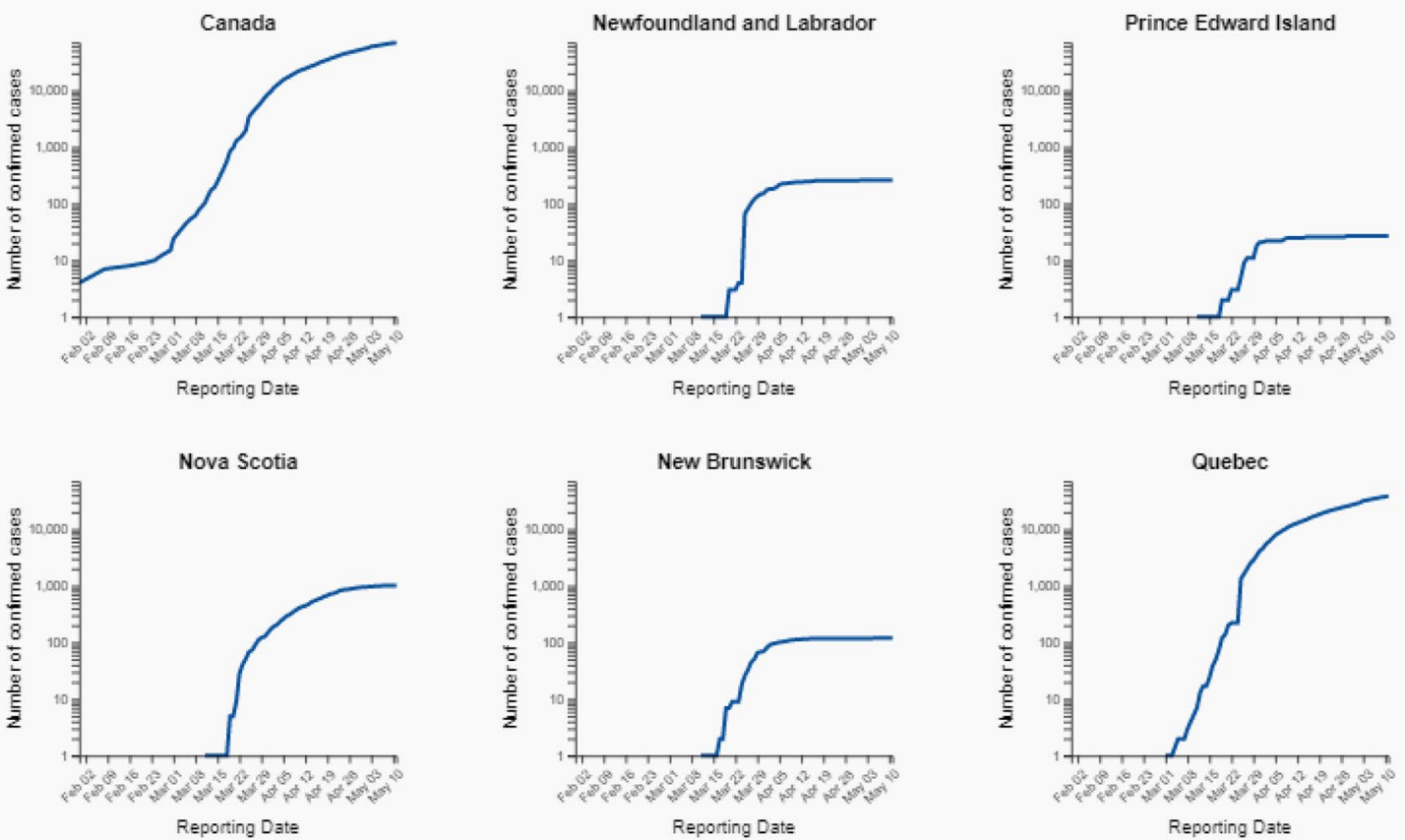

Fig. 6 a Total number of Covid-19 confirmed cases on 11 May, 2020. b Total number of confirmed cases upto 11 May, 2020 (log scale)

measures the best-fitting (Autoregressive Integrated Moving Average) ARIMA or exponential smoothing model (ESM) for one or more dependent variable series. We used IBM SPSS statistics 25 tools with the time series module. In this module, a time series is a set of observations obtained by measuring a single variable regularly over time. Based on known previous time-series value in the covid-19 dataset [2], a new model to predict future covid-19 cases are predicted. Below is the standard ARIMA forecasting Eq. (1). 

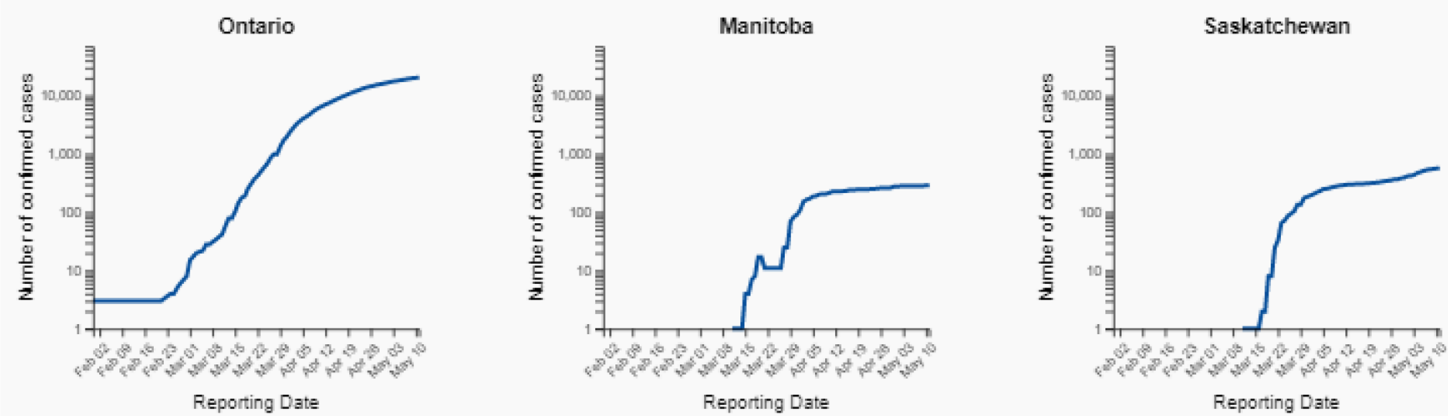

Reporting Date

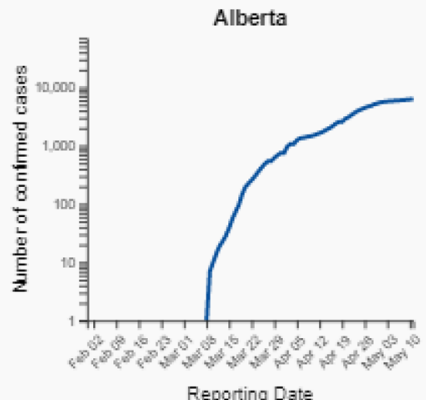

British Columbia
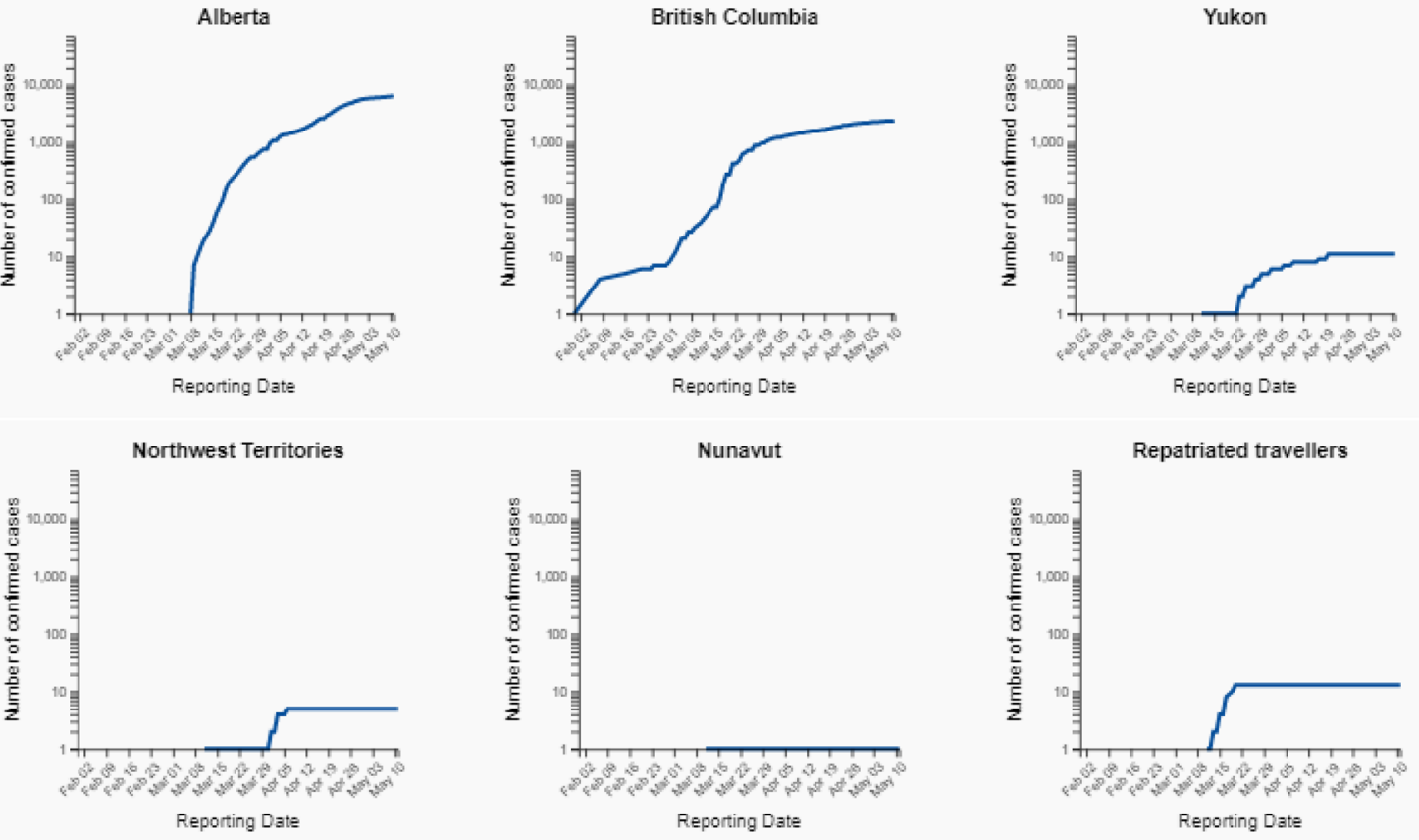

(b)

Fig. 6 (continued)

$Y:=\operatorname{ARIMA}(p, d, q)$

$p$ is the number of autoregressive terms, $d$ is the number of no seasonal differences needed for stationarity, and $q$ is the number of lagged forecast errors in the prediction equation.

In Eqs. (2), (3), (4)), $y$ denotes the $d$ th difference of $Y$, which means:

If $d=0: y t=Y t$.

If $d=1: y t=Y t-Y t-1$.

$$
\begin{aligned}
& \text { If } d=2: y t=(Y t-Y t-1)-(Y t-1-Y t-2) \\
& \quad=Y t-2 Y t-1+Y t-2 .
\end{aligned}
$$

$$
\hat{y}_{t}=\mu+\phi_{1} y_{t-1}+\ldots+\phi_{p} y_{t-p}-\theta_{1} e_{t-1}-\ldots-\theta_{q} e_{t-q} .
$$

We made the following Eq. (6) of ARIMA model where $Y$ is a dependent variable which is confirmed and $Y_{1}, Y_{2}, \cdots$, $Y_{10}$ are Canadian provinces, respectively.

$Y: Y_{1}, Y_{2}, Y_{3}, Y_{4}, Y_{5}, Y_{6}, Y_{7}, Y_{8}, Y_{9}, Y_{10}=\operatorname{ARIMA}(p, d, q)$.

The expert model provided the best fit models suggested by ARIMA equation depicted in Table 1 .

Next Eq. (7) shown the decease prediction where $Y$ is decease variable (Fig. 2).

$Y: Y_{1}, Y_{2}, Y_{3}, Y_{4}, Y_{5}, Y_{6}, Y_{7}, Y_{8}, Y_{9}, Y_{10}=\operatorname{ARIMA}(p, d, q)$.

The general equation of ARIMA shown in Eq. (5), where moving average parameters ( $\theta$ 's), 


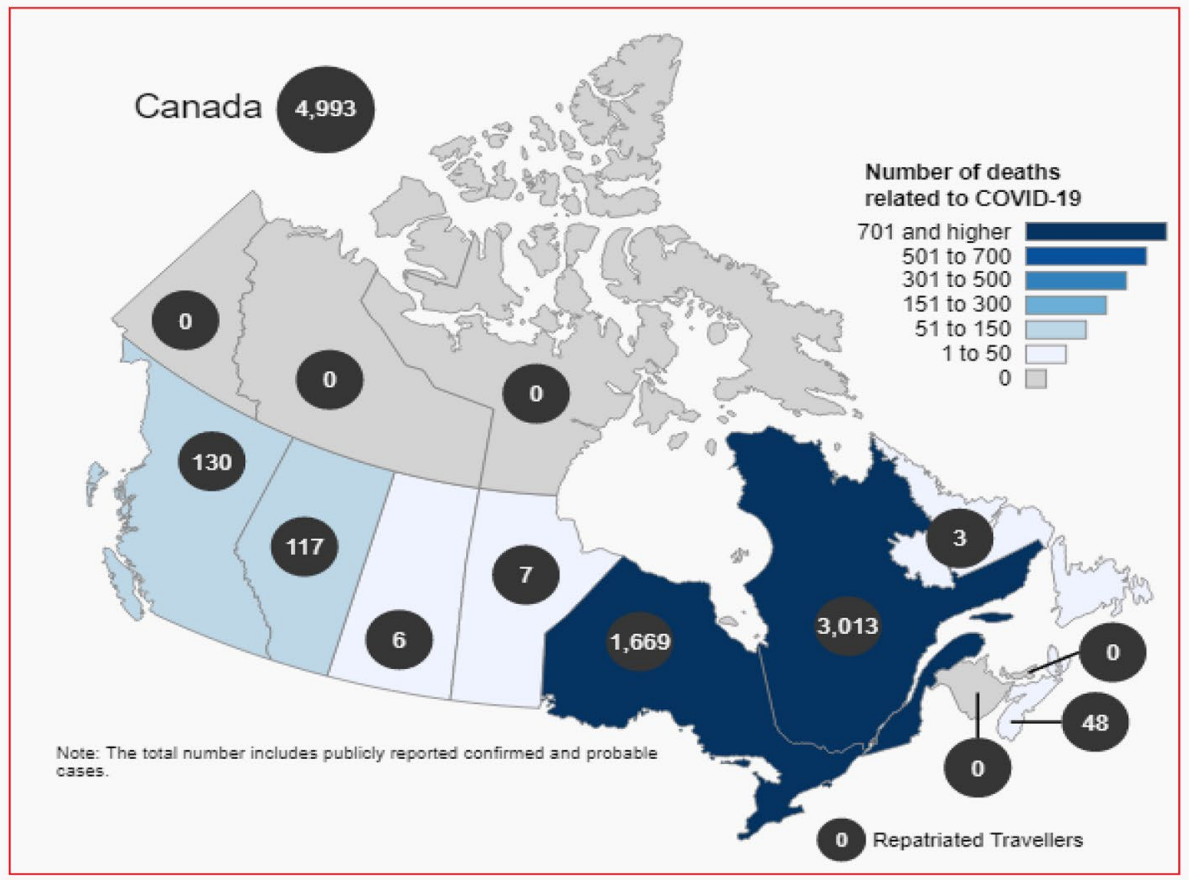

(a)
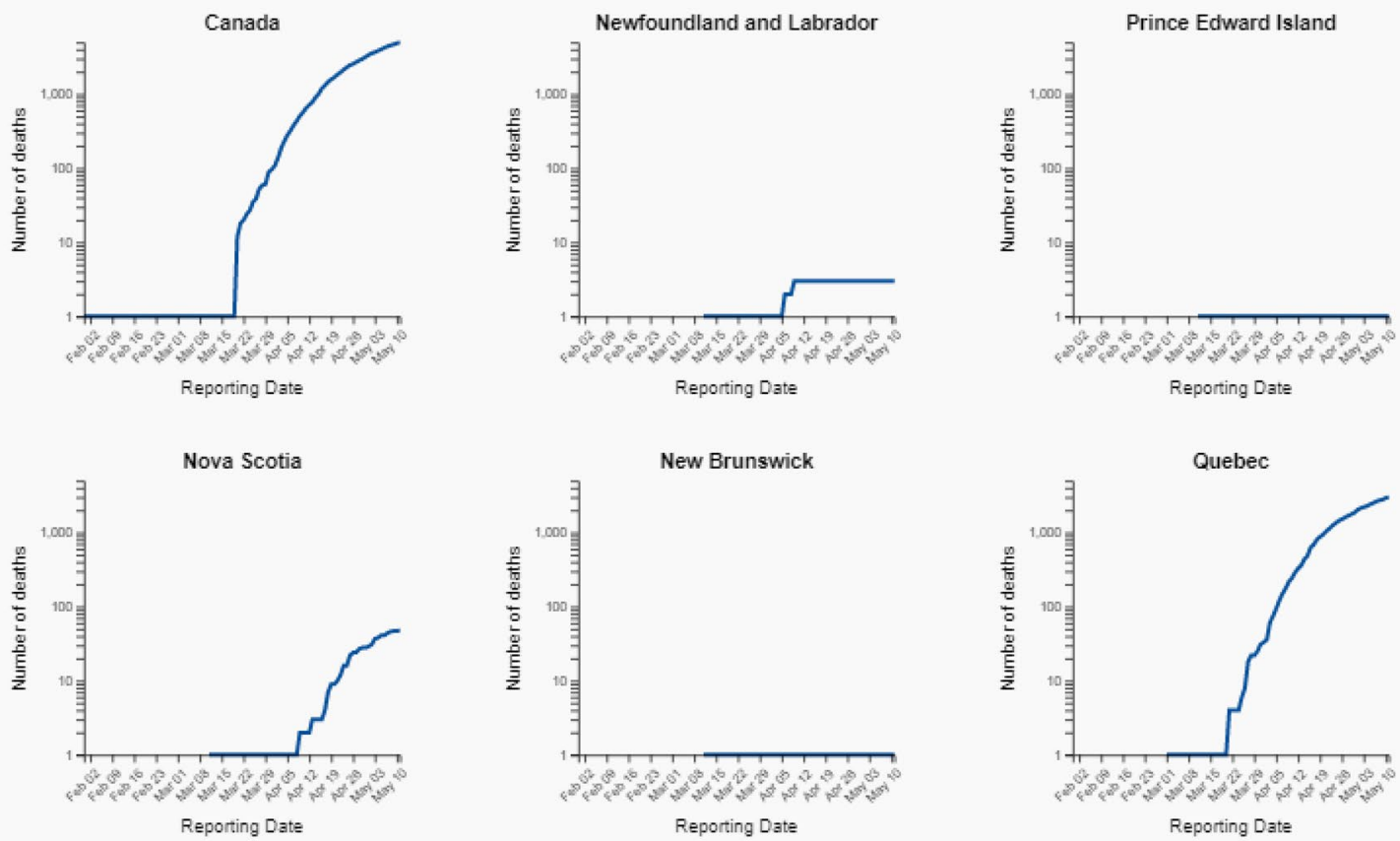

(b)

Fig. 7 a Total number of death cases upto 11 May, 2020. b Total number of death cases upto 11 May, 2020. $\mathbf{c}$ Total number of death cases up to 11 May 2020

\section{Test Data Under Consideration}

The present study used standard and official data set [12] from 12th May to 31 May 2020. The dataset has five major variables named Province, confirmed, recovered, active, and decease. Except for the Province variable, all variables are scale type. The data set is keeping update at the end of each day, having updated records of ten Province and three 

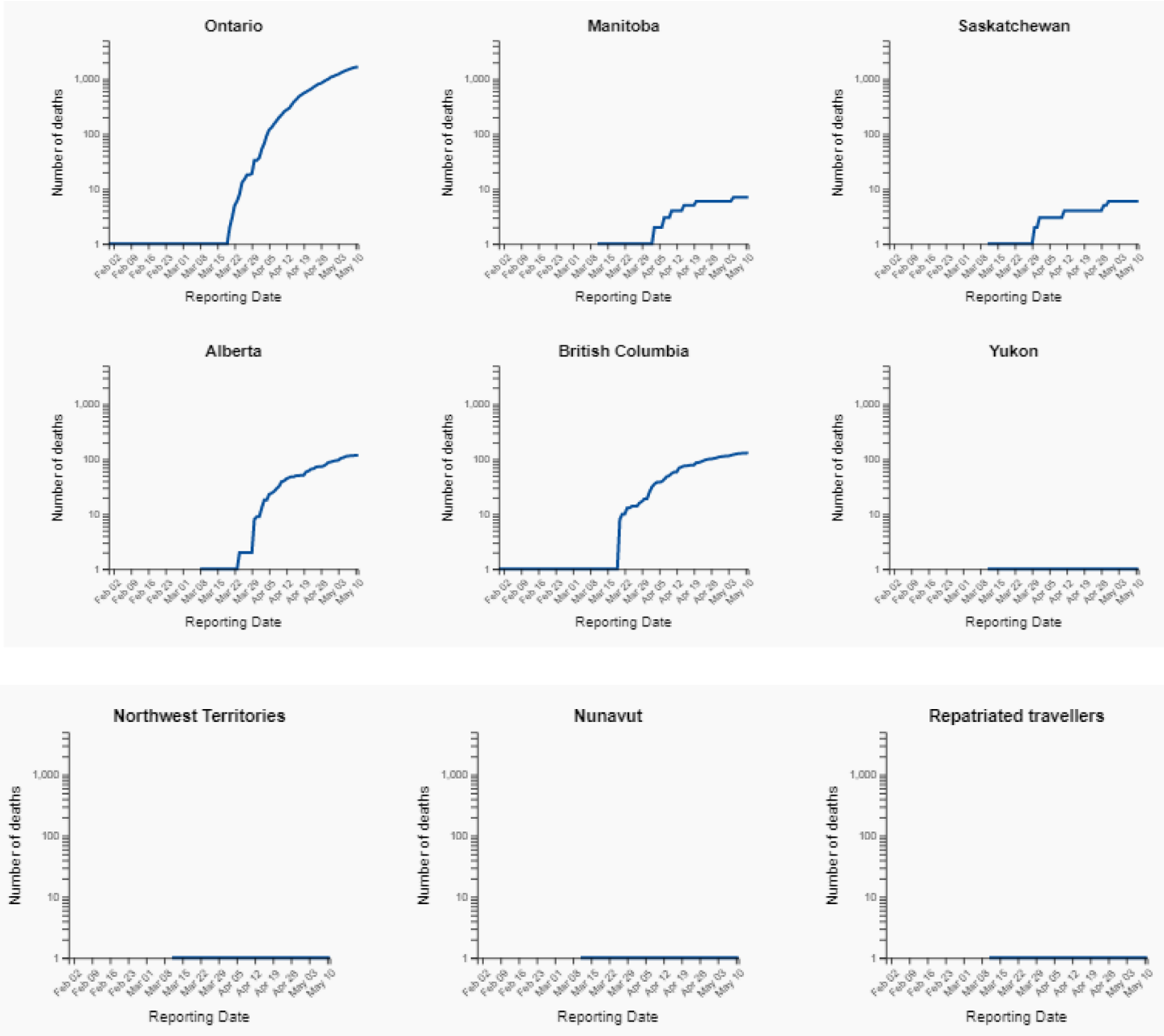

(c)

Fig. 7 (continued)

territories of Canada. The reliability of data samples is calculated by 0.816 using the Cronbach alpha test. Figure 3 depicts the total number of tested individuals up to 11th May, 2020. Table 2 shows the total number of individually tested versus confirmed cases as on 11 May, 2020. Figure 4 depicts the test data for the total number of individuals tested up to 11 May, 2020 (normal scale) (Fig. 5).

Figure $6 \mathrm{a}, \mathrm{b}$ shows the total number of confirmed cases for covid-19 upto 11th May, 2020 in all the provinces and territories of Canada.

Figure $7 \mathrm{a}-\mathrm{c}$ depicts the total number of decreased cases in all the provinces and territories of Canada.

\section{Results and Discussion}

Figure 8a-d shows the status of the total number of tested, confirmed, and decrease cases in the Canadian Provinces Nunavut, Ontario, Quebec, and Yukon. The maximum number of confirmed cases up to 11th May, 2020 has been recorded are 69,981 and death cases of 4993 with a 7403 deviation value.

The number of individuals tested for COVID-19 in Nunavut was 576 as of May 11, 2020. The number of confirmed cases of COVID-19 in Nunavut was 0 as of May 11, 2020. The number of deaths related to COVID-19 in Nunavut was 0 as of May 11, 2020.

The number of individuals tested for COVID19 in Ontario was 433,316 as of May 11, 2020. The number of confirmed cases of COVID-19 in Ontario was 20,546 as of May 11, 2020. The number of deaths related to COVID19 in Ontario was 1669 as of May 11, 2020.

The number of individuals tested for COVID-19 in Quebec was 284,239 as of May 11, 2020. The number of confirmed cases of COVID-19 in Quebec was 38,469 as of May 11, 2020. The number of deaths related to COVID19 in Quebec was 3013 as of May 11, 2020. 

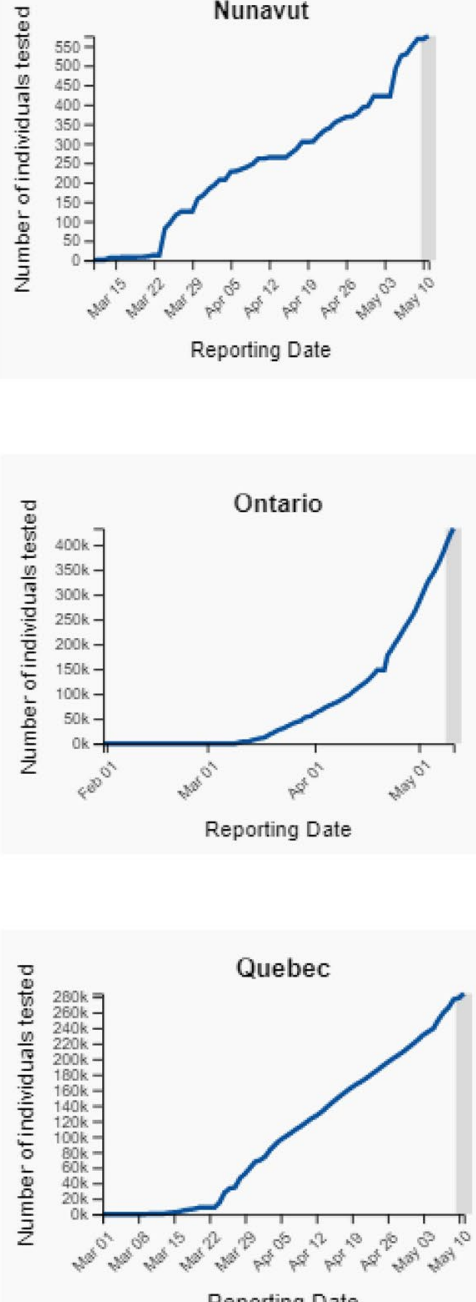

Reporting Date

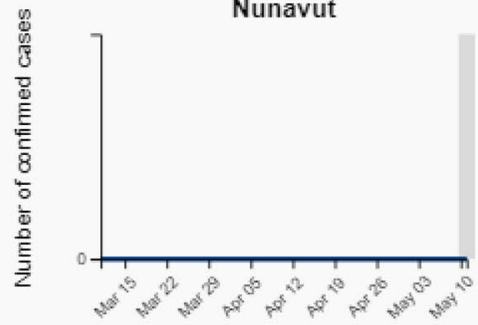

Reporting Date

(a)

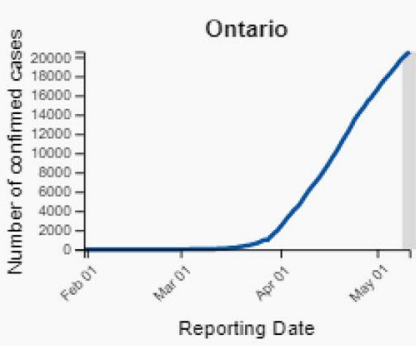

(b)

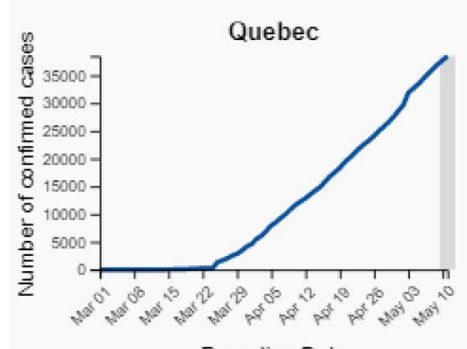

Reporting Date

(c)
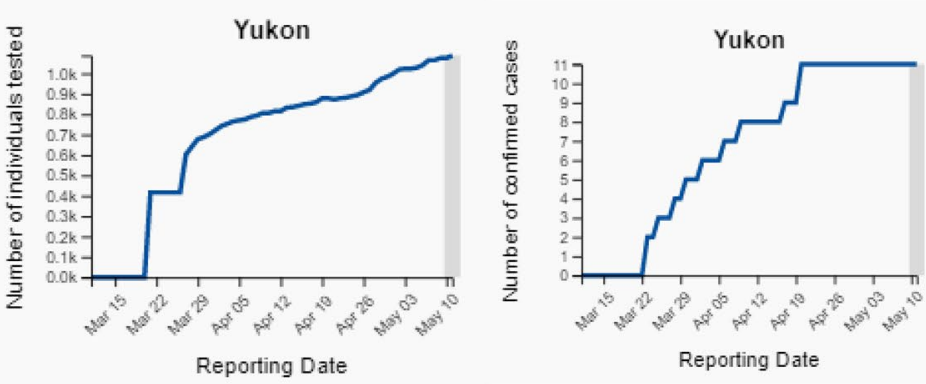

(d)

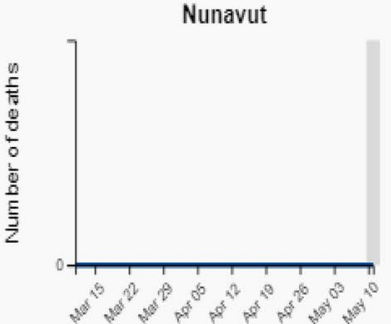

Reporting Date
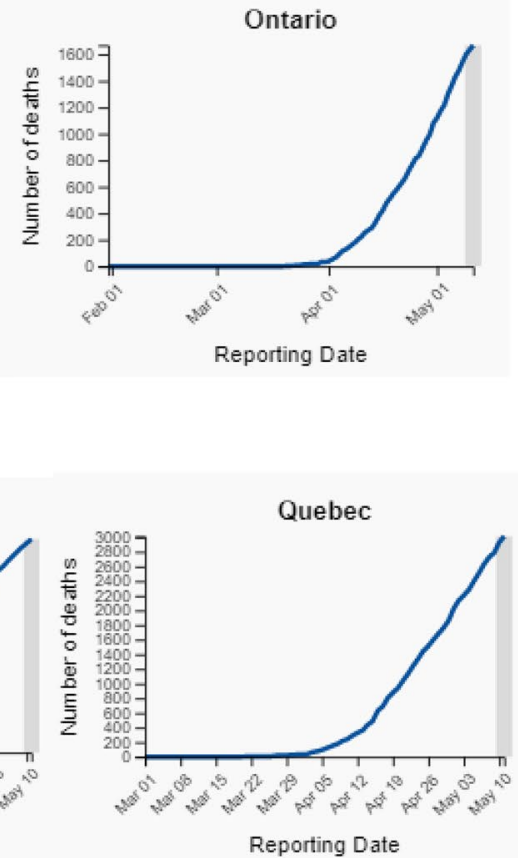

Reporting Date

Yukon

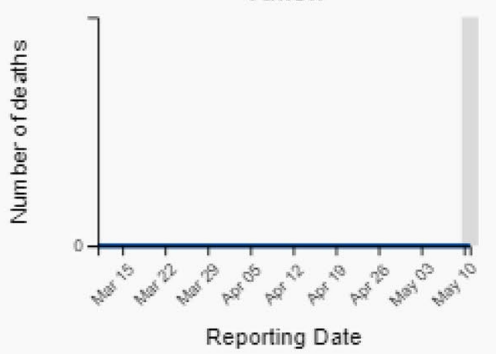

Fig. 8 a The number of individuals tested, confirmed cases and decreased cases in Nunavut. b The number of individual tested, confirmed cases and decreased cases in Ontario. c The number of indi- viduals tested, confirmed cases and decreased cases in Quebec. d The number of individuals tested, confirmed cases, and decreased cases in Yukon 
Table 3 ARIMA model fitting for decease

\begin{tabular}{lrrlrrrr}
\hline Fit statistic & Mean & SE & Minimum & Maximum & 75 & 90 & 95 \\
\hline Stationary $R$-squared & 0.368 & 0.22 & $-1.33 \mathrm{E}-15$ & 0.630 & 0.557 & 0.63 & \multicolumn{1}{c}{0.63} \\
$R$-squared & 0.997 & 0.004 & 0.990 & 1.000 & 1.000 & 1.000 & 1.000 \\
RMSE & 4.179 & 8.054 & 0.000 & 24.219 & 4.398 & 23.086 & 24.219 \\
MAPE & 6.311 & 1.598 & 3.785 & 8.346 & 7.898 & 8.346 & 8.346 \\
MaxAPE & 98.980 & 1.890 & 95.833 & 100.000 & 100.000 & 100.000 & 100.000 \\
MAE & 2.086 & 3.976 & 0.000 & 11.946 & 2.321 & 11.394 & 11.946 \\
MaxAE & 22.272 & 43.674 & 0.000 & 129.902 & 22.899 & 124.085 & 129.902 \\
Normalized BIC & 0.521 & 3.737 & -4.003 & 6.411 & 4.134 & 6.411 & 6.411 \\
\hline
\end{tabular}

Deceased Reported upto 2nd June'2020

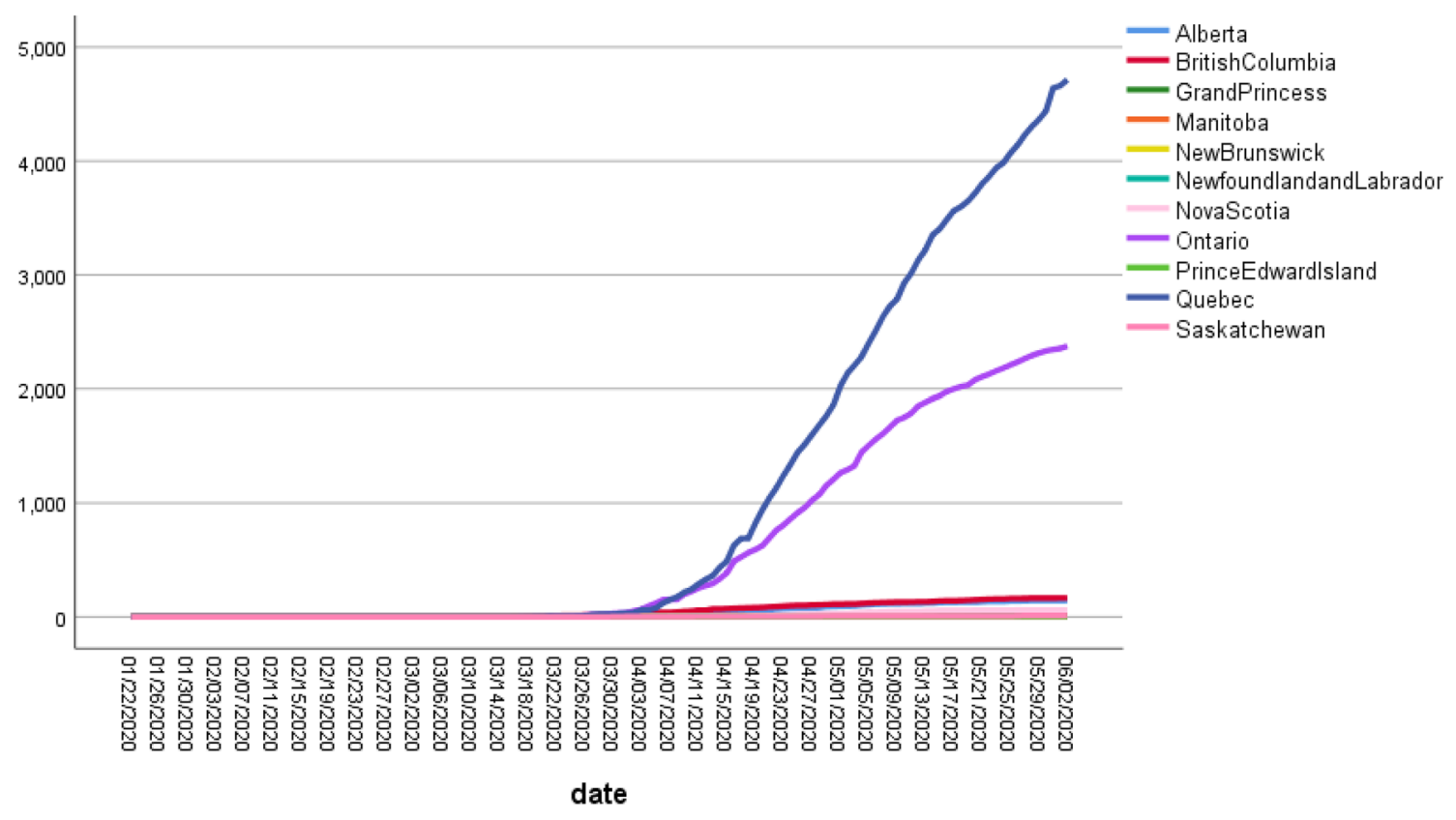

Fig. 9 Zone wise total number of decease reported up to 2nd June 2020

The number of individuals tested for COVID19 in Yukon was 1088 as of May 11, 2020. The number of confirmed cases of COVID-19 in Yukon was 11 as of May 11, 2020. The number of deaths related to COVID19 in Yukon was 0 as of May 11, 2020. Figure 9 depicts the Zone wise total number of decease reported up to 2nd June 2020. and Fig. 11 shows the decease prospects for the next 27 days up to 30 June 2020.

Table 3 shows the model fitting for the decrease. Figure 10 shows the expert model's for decease prediction for the next 27 days up to 30 June 2020 . One the one hand, the blue lines spot forecast and red curve depict the observed cases in the dataset. The expert model proves the forthcoming human deaths may be reported in the Alberta (around 165), British Columbia (around 180), Ontario (around 2700), Quebec (around 6900), Saskatchewan (around 11), and least chances are found in rest of provinces.
Figure 11 visualizes the future deceases count in Canadian provinces. We found four provinces (Alberta, British Columbia, Ontario, and Quebec) where future deaths chances are more and entitled most decease prone zones in Canada. Among the four, the highest predicted decease count is 6922 in Quebec. Hence, the republic of Canada needs to more alert and care about the dangerous conditions ahead. According to results, we put three provinces in the least deceases prone zones depicted left side of the graph.

Figure 12 plots date wise status of confirmed cases reported in distinct provinces of Canada. More than 50,000 humans are infected with covid-19 in Manitoba, and Ontario has around 30,000 cases, which is massive count confirmed cases. Less than 10,000 cases are reported in other provinces. Hence, highly red zone provinces are found in Manitoba and Ontario. 

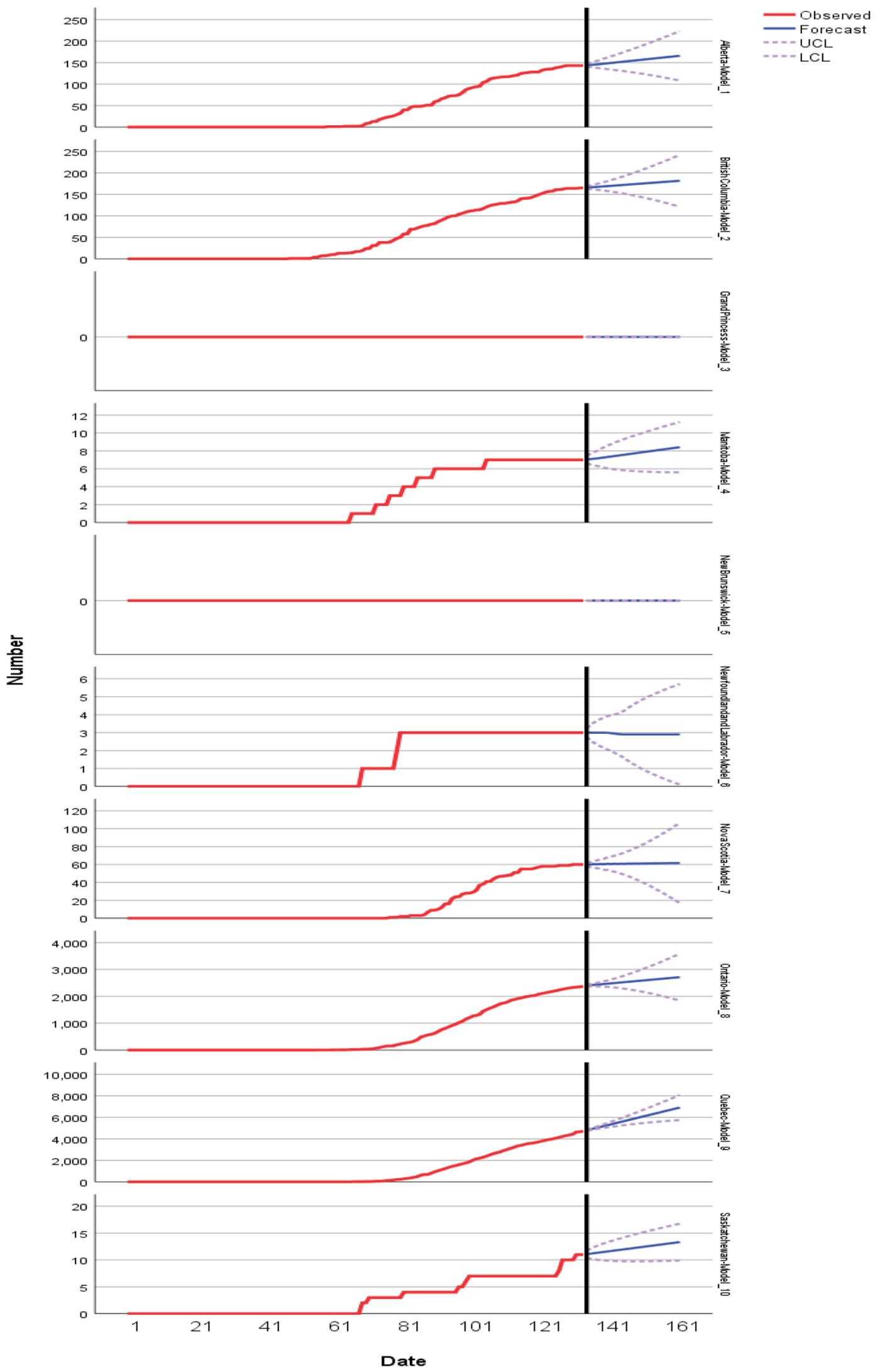

Fig. 10 ARIMA Model's decease prediction for next 27 days up to 30 June 2020 
Fig. 11 Decease prospects for next 27 days up to 30 June 2020

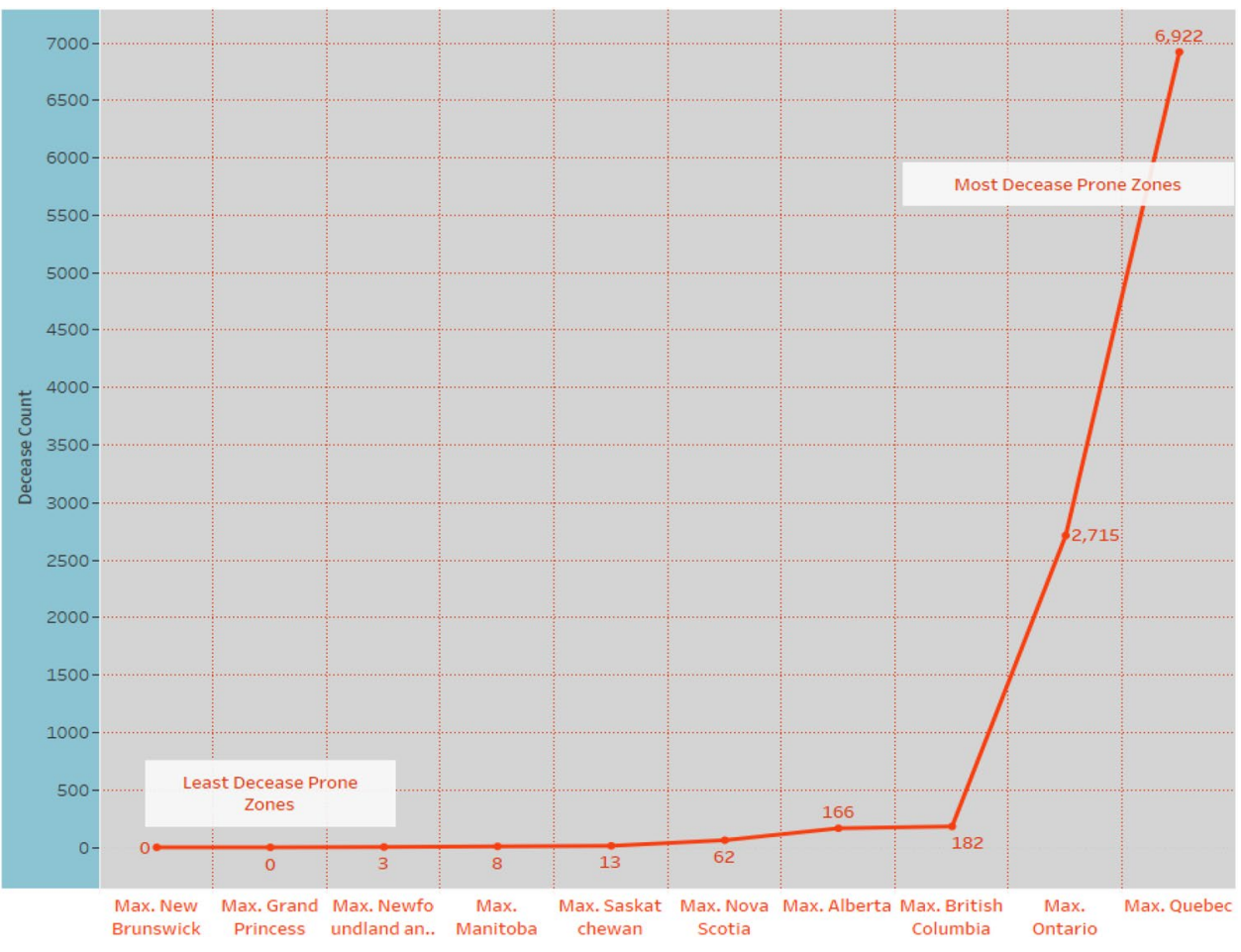

Fig. 12 Confirmed individuals up to 02nd June 2020

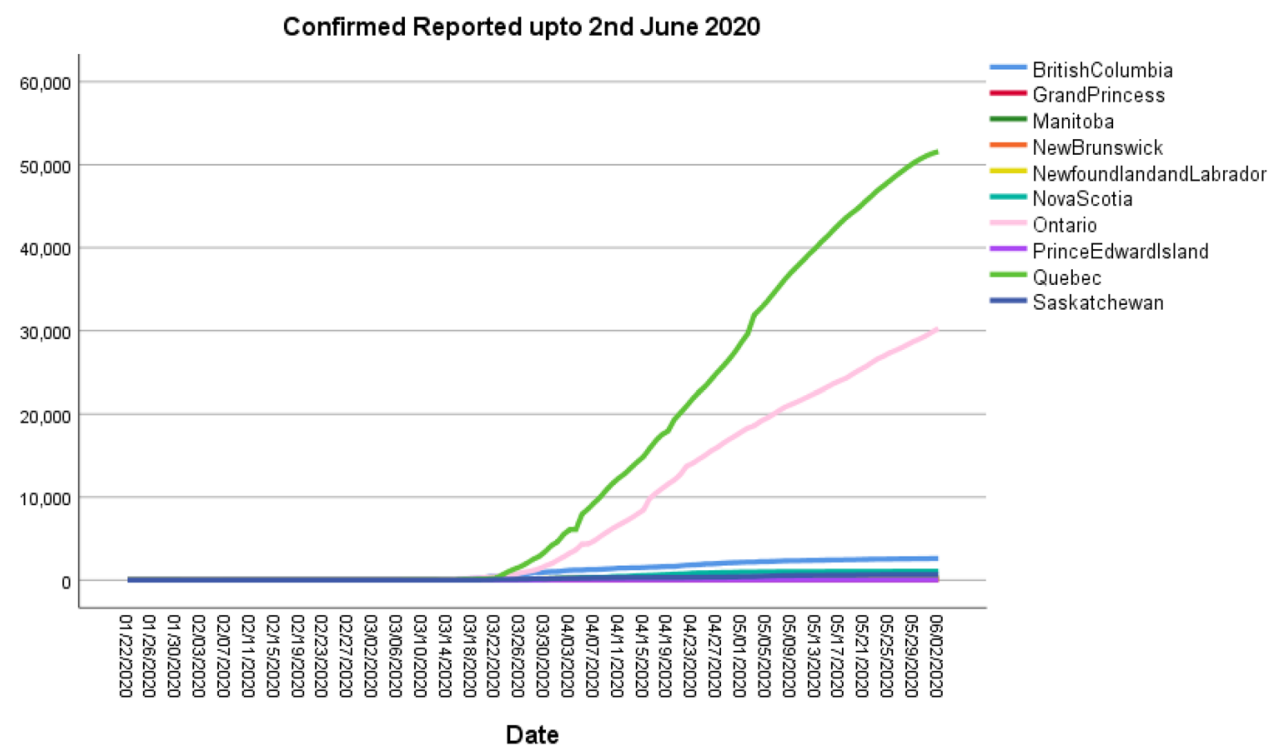

Figure 13 shows confirmed predictions for the next 27 days up to 30 June 2020. Around 3000 confirmed cases may be reported in British Columbia, and Ontario may face around 40,000 confirmed cases. Figure 14 displays the predicted count of the number of confirmed cases in the nine provinces. Four provinces are predicted where huge confirmation is seen like Nova Scotia, British Columbia, Ontario, and Quebec. The least prediction counts are observed in the least prospecting confirmed zones. Table 4 shows the model fitting for confirmed cases in all the provinces of Canada, including territories. 


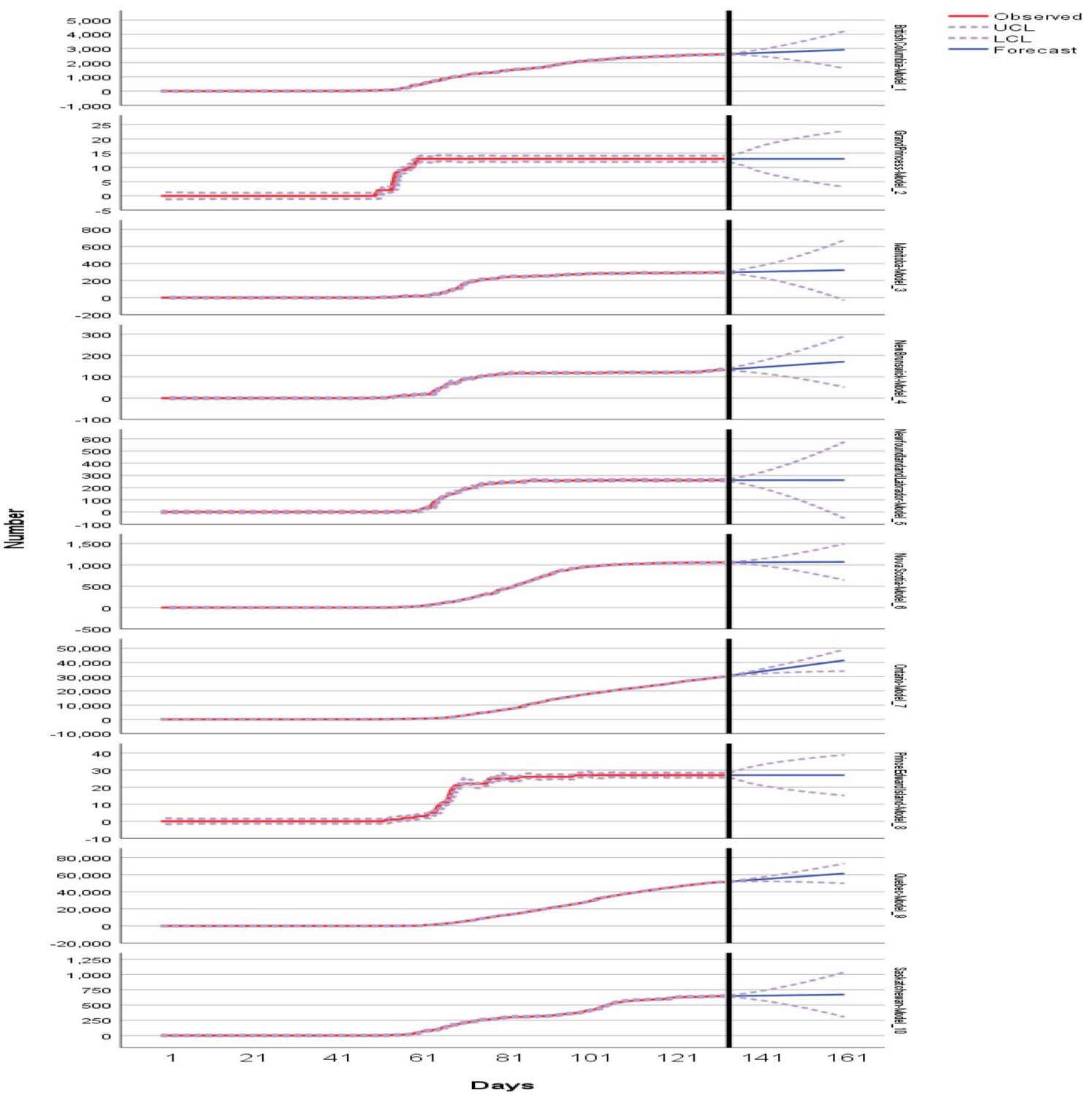

Fig. 13 ARIMA Model's confirmed prediction for next 27 days up to 30 June 2020

\section{Conclusion}

This paper presented a predictive model to estimate the future human decease infected with Covid-19 for all the provinces of Canada, including three territories. The findings of the study explored the strong relationship between patient decease rate with recovery and active status. On one hand, active cases impacted the decease rate, and on the other hand, patient deceases are effected by the recovered patient. Following the government Covid-19 guidelines, yet to be 
Fig. 14 Confirmed prospects for next 27 days up to 30 June 2020

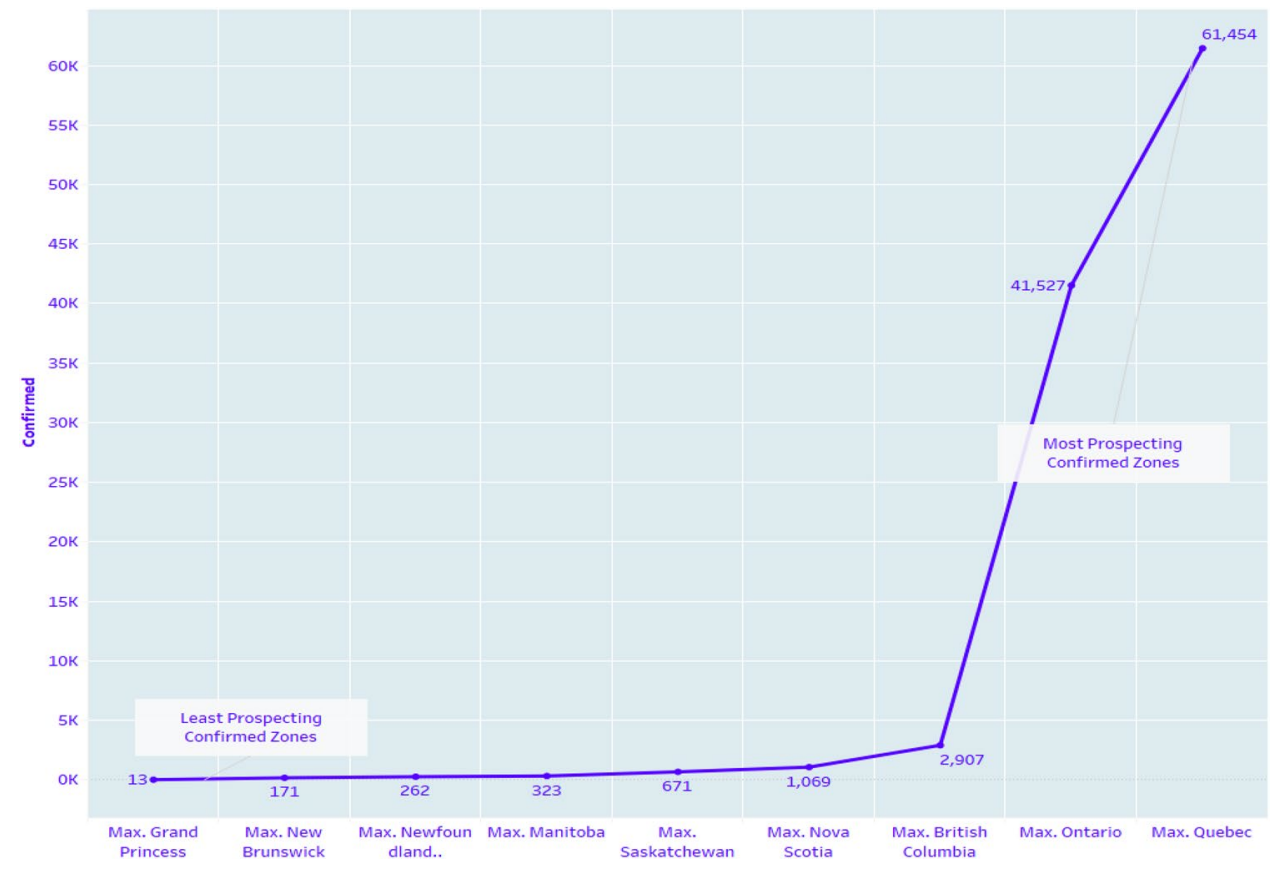

\begin{tabular}{lrrrrrrr}
\hline Fit statistic & Mean & SE & Minimum & Maximum & 75 & 90 & 95 \\
\hline Stationary $R$-squared & 0.436 & 0.129 & 0.250 & 0.700 & 0.490 & 0.680 & 0.700 \\
$R$-squared & 0.998 & 0.002 & 0.993 & 1.000 & 1.000 & 1.000 & 1.000 \\
RMSE & 38.582 & 71.832 & 0.533 & 212.54 & 48.66 & 203.724 & 212.54 \\
MAPE & 5.972 & 1.508 & 2.808 & 7.726 & 7.24 & 7.717 & 7.726 \\
MaxAPE & 99.540 & 1.005 & 97.138 & 100.000 & 100.000 & 100.000 & 100.000 \\
MAE & 17.644 & 32.157 & 0.101 & 95.422 & 23.901 & 91.452 & 95.422 \\
MaxAE & 245.591 & 458.86 & 4.362 & 1263.023 & 315.891 & 1230.92 & 1263.02 \\
Normalized BIC & 4.047 & 3.931 & -1.148 & 10.755 & 7.206 & 10.648 & 10.755 \\
\hline
\end{tabular}

Table 4 ARIMA model fitting for confirmed cases
ARIMA $(2,2,1)$

ARIMA $(1,2,1)$

ARIMA $(0,0,0)$

ARIMA $(0,1,4)$

ARIMA $(0,0,0)$

ARIMA $(1,1,11)$

ARIMA $(1,2,10)$

ARIMA $(0,2,5)$

Brown

$\operatorname{ARIMA}(0,1,0)$ enhancement are observed in active, recovered, and decease count. Therefore, highly decease prospects are found in the active and recovered cases. Further, present models alerted red zone states to take precautionary measures from the pandemic (Table 5).

Acknowledgements The first author wishes to thank Dr. O.P. Malik, Professor Emeritus, Department of Electrical and Computer Engineering, Schulich School of Engineering, University of Calgary, Calgary, Alberta, CANADA for continuous support, guidance, encouragement and for providing advance research facilities for post-doctorate research at the University of Calgary, Alberta, CANADA. The corresponding author wishes to thank Dr. Zoltán Illés, Department of Media and Educational Informatics, Eötvös Loránd University, Budapest, Hungary, and Prof. Veronika Stoffová, Department of Mathematics and 
Computer Science, Trnava University, Slovakia, for motivated to write this article and continuous support throughout entire Ph.D study.

Funding Open access funding provided by Eötvös Loránd University.

\section{Complaince with Ethical Standards}

Conflict of interest The authors declare that they have no conflict of interest.

Open Access This article is licensed under a Creative Commons Attribution 4.0 International License, which permits use, sharing, adaptation, distribution and reproduction in any medium or format, as long as you give appropriate credit to the original author(s) and the source, provide a link to the Creative Commons licence, and indicate if changes were made. The images or other third party material in this article are included in the article's Creative Commons licence, unless indicated otherwise in a credit line to the material. If material is not included in the article's Creative Commons licence and your intended use is not permitted by statutory regulation or exceeds the permitted use, you will need to obtain permission directly from the copyright holder. To view a copy of this licence, visit http://creativecommons.org/licenses/by/4.0/.

\section{References}

1. Huang C, Wang Y, Li X, Ren L, Zhao J, Hu Y, Zhang L, Fan G, Xu J, Gu X, et al. Clinical features of patients infected with 2019 novel coronavirus in Wuhan. China Lancet. 2020;395(10223):497-506.

2. WHO. https://www.who.int/health-topics/coronavirus\#tab=tab_1. Accessed 21 May 2020

3. Li L, Yang Z, Dang Z, Meng C, Huang J, Meng H, Wang D, Chen G, Zhang J, Peng H, Shao Y. Propagation analysis and prediction of the COVID-19. Infect Dis Model. 2020;5:282-92.

4. Tomar A, Gupta N. Prediction for the spread of COVID-19 in India and effectiveness of preventive measures. Sci: Total Environ; 2020. https://doi.org/10.1016/j.scitotenv.2020.138762.
5. PIB. https://pib.gov.in/pressreleaseiframepage.aspx?prid=16010 95. 2020.

6. Wuhan Municipal Health Commission. Report on the Current Situation of Pneumonia in Wuhan (2019-12-31). Available online: https://wjw.wuhan.gov.cn/front/web/showDetail/2019123108989. Accessed 19 Feb 2020.

7. World Health Organization. Coronavirus disease 2019 (COVID19): situation report. 2020;70.

8. Gorbalenya AE, et al. Severe acute respiratory syndrome-related coronavirus - the species and its viruses, a statement of the Coronavirus Study Group. bioRxiv 2020.

9. Knoops K, Kikkert M, Worm SH, Zevenhoven-Dobbe JC, van der Meer Y, Koster AJ, Mommaas AM, Snijder EJ. SARS-coronavirus replication is supported by a reticulovesicular network of modified endoplasmic reticulum. PLoS Biol. 2008;6:e226.

10. Xu XT, Chen P, Wang JF, Feng JN, Zhou H, Li X, Zhong W, Hao $\mathrm{P}$. Evolution of the novel coronavirus from the ongoing Wuhan outbreak and modeling of its spike protein for risk of human transmission. Sci China Life Sci. 2020;63:457.

11. National Health Commission of the People's Republic of China and National Administration of Traditional Chinese Medicine. Diagnosis and Treatment Scheme for Novel Coronavirus Pneumonia (Trial) 6th Edition. Available online: https://www.nhc.gov. cn/xcs/zhengcwj/202002/8334a8326dd94d329df351d7da8aef c2.shtml. Accessed 19 Feb 2020.

12. Coronavirus disease (COVID-19): outbreak update, available at: https://www.canada.ca/en/public-health/services/diseases/2019novel-coronavirus-infection.html.

13. https://raw.githubusercontent.com/CSSEGISandData/COVID -19/master/csse_covid_19_data/csse_covid_19_time_series/ time_series_covid19_confirmed_global.csv.

Publisher's Note Springer Nature remains neutral with regard to jurisdictional claims in published maps and institutional affiliations. 